\title{
Genetic mapping of eight SH3 domain genes on seven mouse chromosomes
}

\author{
Chun G. Lee ${ }^{1}$, Herbert C. Morse III' ${ }^{2}$, Brian K. Kay ${ }^{3}$, Christine A. Kozak ${ }^{1 *}$ \\ ${ }^{1}$ Laboratory of Molecular Microbiology, National Institute of Allergy and Infectious Diseases, Bldg. 4, Room 329, 4 Center Drive MSC 0460, \\ Bethesda, Maryland 20892-0460, USA \\ ${ }^{2}$ Laboratory of Immunopathology, National Institute of Allergy and Infectious Diseases, Bethesda, Maryland 20892, USA \\ ${ }^{3}$ Department of Pharmacology, University of Wisconsin-Madison, Madison, Wisconsin 53706, USA
}

Received: 28 September 1998 / Accepted: 2 December 1998

The process of screening cDNA expression libraries with phageoptimized peptide ligands, termed cloning of ligand targets (COLT), was recently used to isolate a series of SH3 domaincontaining proteins (Sparks et al. 1996). Among the 18 SH3 domain-containing proteins identified, nine were previously unreported from mouse. The structures of seven of the proteins whose genes are mapped in this study are diagrammed in Fig. 1. The function of many of the mouse proteins is being actively pursued by many laboratories. Three of the proteins, SH3P4, SH3P8, and SH3P14, are highly related in structure and have been discovered to bind synaptojanin and dynamin, and to be involved in endocytosis (de Heuvel et al. 1997; Ringstad et al. 1997). This family of proteins, which has also been discovered in human (Giachino et al. 1997), has been termed endophilin 1, 2, and 3. SH3P8 was also identified as a gene fused to MLL in human acute myeloid leukemia (So et al. 1997) and as a protein that binds to the Gag protein of murine leukemia viruses in a yeast two-hybrid screen (W. Kim, T. Torrey, H. Morse, unpublished observations). SH3P9, renamed amphiphysin II because of its strong similarity to amphiphysin, has been shown to be a component of the endocytic machinery (Butler et al. 1997; Ramjaun et al. 1997) as well as the cytoskeleton, where it may regulate the $\mathrm{c}-\mathrm{A} b l$ tyrosine kinase (Kadlec and Pendergast 1997). SH3P12 has been observed to interact with c- $\mathrm{Cbl}$ in cells where it may play a role in both signal transduction pathways and regulation of the cytoskeleton (Ribon et al. 1998).

To learn more about the genes for the seven novel mouse proteins, we set out to map their chromosomal locations. Two sets of multilocus genetic crosses were analyzed for inheritance of the mouse genes encoding the SH3 family genes: (NFS/N or C58/J $\times$ M. m. musculus) $\times$ M. m. musculus (NMM and CMM; Kozak et al. $1990)$ and $(\mathrm{NFS} / \mathrm{N} \times$ x $M$. spretus $) \times M$. spretus or C58/J (NSS and NSC; Adamson et al. 1991). Probes were prepared by polymerase chain reaction (PCR) from the nine cDNA clones, seven of which have been deemed full-length (Sparks et al. 1996), and used in blots of restriction enzyme digests of genomic DNA.

Inheritance patterns were described for eight polymorphic fragments identified by the seven different probes. Restriction fragments used to identify specific loci are given in Table 1 . Seven loci were typed in the M. spretus crosses and six loci in the $M . m$. musculus crosses. Comparisons of the inheritance patterns of these fragments with those of over 1200 loci previously typed and mapped in these crosses showed that eight loci could be positioned on seven chromosomes. Two genes were mapped to Chromosome (Chr) 19, but they were separated by more than $20 \mathrm{cM}$. The recombination data used to derive the map locations are given in Table 2.

In all but one case, all restriction fragments identified by a

Correspondence to: C.A. Kozak single probe could be mapped to the same locus. The exception, probe SH3P13, identified loci on two mouse chromosomes, Chrs 2 and 7. The two corresponding loci, Sh $3 d 2 c 1$ and $S h 3 d 2 c 2$, were identified in both sets of crosses, indicating that neither represented a species-specific pseudogene. Previous data have shown that the human homolog of this $\mathrm{SH} 3$ domain gene, originally termed SH3GL3, is located at 15q24 (Giachino et al. 1997). One of the mouse loci identified by this probe, $\operatorname{Sh} 3 d 2 c 2$, mapped to a region of Chr 7 homologous to $15 q 21-26$, identifying it as the mouse homolog of human SH3GL3. The nature of the second locus, $\operatorname{Sh} 3 d 2 c$, remains to be determined.

Human map locations have also been defined for $\operatorname{Sh} 3 d 2 a$ and $\operatorname{Sh} 3 d 2 b$. The homolog of Sh3d2a (SH3GL2) was mapped to 9p22, which is consistent with its position on mouse Chr 4 . We previously reported the map location for $S h 3 d 2 b$ on mouse Chr 17 (Torrey et al. 1998), consistent with the human location for SH3GL1 on 19p13.3. Finally, another SH3 domain gene, Amph (amphiphysin), maps to mouse Chr 13 and human 7p14-p13 (Jenkins et al. 1995).

None of the other genes have been mapped in human, although mouse map locations predict positions for SH3D4 and SH3D5 on human chromosomes 8 p21-23 and 10q respectively. Since map locations for $D b n 1 l$ and $S h 3 d 3$ place them in regions with homology to two or more human chromosomes, we attempted to make

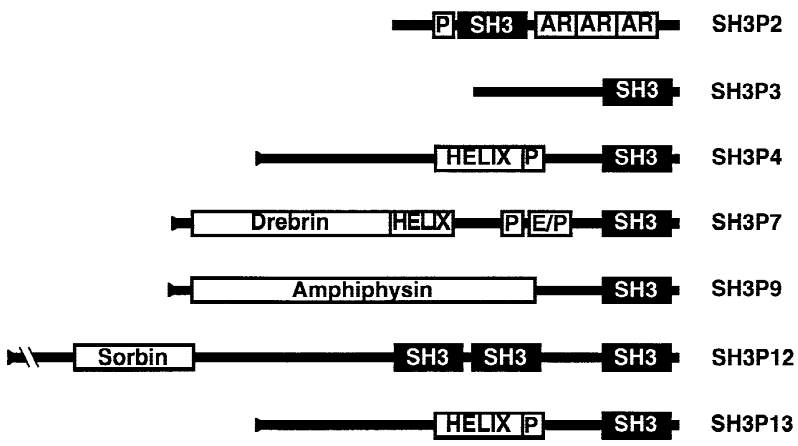

Fig. 1. Schematic diagram of the seven novel mouse proteins whose chromosome locations were mapped in this study. The proteins were identified in a COLT screen of a mouse 16-day embryo cDNA library (Sparks et al. 1996). Diagrams are to scale, with the SH3 domains (black boxes) representing approximately 60 amino acids. $\mathrm{AR}=$ ankyrin repeats; $\mathrm{E} / \mathrm{P}=$ glutamate/proline-rich segments; HELIX = putative $\square$-helical segments; and $\mathrm{P}=$ proline-rich segments. Regions with a high degree of sequence identity to amphiphysin, drebrin, and sorbin are also noted with boxes. GenBank accession numbers of the proteins are U58888 (SH3P2), U58889 (SH3P3), U58886 (SH3P4), U58884 (SH3P7), U60884 (SH3P9), U58883 (SH3P12), and U58887 (SH3P13). All reading frames are full-length, except for $\mathrm{SH} 3 \mathrm{P} 2$ and $\mathrm{SH} 3 \mathrm{P} 3$. 
Table 1. Restriction fragments used to identify SH3 domain loci in two sets of multilocus crosses.

\begin{tabular}{|c|c|c|c|c|c|c|c|}
\hline \multirow[b]{2}{*}{ Locus } & \multirow[b]{2}{*}{ Name } & \multirow[b]{2}{*}{ Probe $^{a}$} & \multirow[b]{2}{*}{ Chr } & \multirow[b]{2}{*}{ Enzyme } & \multicolumn{2}{|c|}{ Fragment Size $(\mathrm{Kb})^{\mathrm{b}}$} & \multirow[b]{2}{*}{ Crosses Typed ${ }^{\circ}$} \\
\hline & & & & & NFS/N & M. spretus & \\
\hline Amph2 & Amphiphysin 2 & SH3P9 & 18 & Pst $\mathrm{I}$ & 4.3 & 4.6 & NSS, NSC \\
\hline Dbnil & Debrin 1 like & SH3P7 & 11 & $S a c \mathrm{I}$ & $3.2,3.0$ & $4.4,3.0$ & NSS, NSC \\
\hline \multirow[t]{2}{*}{$\operatorname{Sh} 3 d 2 a$} & SH3 domain protein $2 \mathrm{~A}$ & SH3P4 & 4 & Sst $\mathrm{I}$ & 6.7 & & NMM, CMM \\
\hline & & & & $P v u \mathrm{II}$ & 8.6 & 7.9 & NSS, NSC \\
\hline \multirow{2}{*}{$\operatorname{Sh} 3 d 2 c 1$} & $\mathrm{SH} 3$ domain protein $2 \mathrm{C} 1$ & SH3P13 & 2 & $B g l I I$ & 16.0 & & NMM, CMM \\
\hline & & & & PvuII & 10.1 & 6.5 & NSS, NSC \\
\hline \multirow[t]{2}{*}{$\operatorname{Sh} 3 d 2 c 2$} & $\mathrm{SH} 3$ domain protein $2 \mathrm{C} 2$ & SH3P13 & 7 & $B g l I I$ & $11.2,4.6$ & & NMM, CMM \\
\hline & & & & $P v u \mathrm{II}$ & & 5.7 & NSC \\
\hline \multirow[t]{2}{*}{$\operatorname{Sh} 3 d 3$} & SH3 domain protein 3 & SH3P2 & 19 & SacI & $23.0,6.2$ & & NMM, CMM \\
\hline & & & & ApaI & $9.2,7.1$ & $9.0,5.8$ & NSS, NSC \\
\hline Sh $3 d 4$ & SH3 domain protein 4 & SH3P3 & 14 & Bam $\mathrm{HI}$ & 18.8 & & NMM, CMM \\
\hline \multirow[t]{2}{*}{$\operatorname{Sh} 3 d 5$} & SH3 domain protein 5 & SH3P12 & 19 & SacI & 16.0 & & NMM, CMM \\
\hline & & & & ApaI & 3.8 & 8.7 & NSS, NSC \\
\hline
\end{tabular}

a Probes were prepared by PCR amplification with oligonucleotides flanking the site of insertion of the various cDNAs in the pEXlox plasmid. cDNA clones are described elsewhere (Sparks et al. 1996).

${ }^{\mathrm{b}}$ Fragment sizes are given only for variant-sized fragments typed in progeny DNAs. Loci typed in the M. m. musculus crosses produced fragments of identical sizes in NFS/N and $\mathrm{C} 58 / \mathrm{J}$.

${ }^{\mathrm{c}}$ Crosses: NMM, $(\mathrm{NFS} / \mathrm{N} \times$ M. m. musculus $) \times M . m$. Musculus

CMM, $(\mathrm{C} 58 / \mathrm{J} \times M$. m. musculus $) \times M$. m. musculus

$\mathrm{NSS},(\mathrm{NFS} / \mathrm{N} \times M$. spretus $) \times M$. spretus

$\mathrm{NSC},(\mathrm{NFS} / \mathrm{N} \times$ M. spretus $) \times \mathrm{C} 58 / \mathrm{J}$

Table 2. Recombination frequencies for the SH3 domain genes and flanking marker loci.

\begin{tabular}{|c|c|c|c|c|c|}
\hline \multirow[b]{2}{*}{$\mathrm{Chr}$} & \multirow[b]{2}{*}{ Locus $1^{\mathrm{a}}$} & \multirow[b]{2}{*}{ Locus 2} & \multicolumn{2}{|c|}{ No. recombinant/total } & \multirow[b]{2}{*}{$\begin{array}{l}\text { Recombination } \\
\text { distances } \pm \mathrm{SE}^{\mathrm{b}}\end{array}$} \\
\hline & & & $\begin{array}{l}\text { M. spretus } \\
\text { crosses }\end{array}$ & $\begin{array}{l}\text { M. m. musculus } \\
\text { crosses }\end{array}$ & \\
\hline \multirow[t]{4}{*}{2} & $I l 2 r a$ & Cacnb2 & $2 / 94$ & $1 / 67$ & $1.9 \pm 1.1$ \\
\hline & Cacnb2 & $\operatorname{Sh} 3 d 2 c 1$ & $1 / 92$ & $1 / 30$ & $1.6 \pm 1.1$ \\
\hline & $\underline{S h} 3 d 2 c 1$ & Cchnla & $0 / 96$ & $0 / 82$ & $(1.7)$ \\
\hline & $\operatorname{Sh} 3 d 2 c 1$ & Vav2 & $0 / 85$ & $5 / 113$ & $2.5 \pm 1.1$ \\
\hline \multirow[t]{3}{*}{4} & D4Rp18 & Tyrpl & $0 / 65$ & $1 / 116$ & $0.6 \pm 0.6$ \\
\hline & Tyrpl & $\underline{\operatorname{Sh} 3 d 2 a}$ & $0 / 74$ & $4 / 41$ & $3.5 \pm 1.7$ \\
\hline & $\operatorname{Sh} 3 d 2 a$ & Ifna & $1 / 83$ & $0 / 37$ & $0.8 \pm 0.8$ \\
\hline \multirow[t]{2}{*}{7} & $A g c$ & $\underline{S h} 3 d 2 c 2$ & $4 / 74$ & $2 / 121$ & $3.1 \pm 1.2$ \\
\hline & $\operatorname{Sh} 3 d 2 c 2$ & Tyr & $3 / 70$ & $5 / 130$ & $4.0 \pm 1.4$ \\
\hline \multirow[t]{3}{*}{11} & $G k$ & Dbnll & $0 / 58$ & & $(5.0)$ \\
\hline & Dbnll & Gabral & $16 / 80$ & & $20.0 \pm 4.5$ \\
\hline & Gabral & Olfrlo & $2 / 80$ & & $2.5 \pm 1.7$ \\
\hline \multirow[t]{3}{*}{14} & Blk & $\operatorname{Sh} 3 d 4$ & & $5 / 59$ & $8.5 \pm 3.6$ \\
\hline & Sh $3 d 4$ & sys & & $0 / 100$ & $(3.0)$ \\
\hline & Sys & Htr $2 a$ & & $1 / 98$ & $1.0 \pm 1.0$ \\
\hline \multirow[t]{4}{*}{18} & $T t r$ & Amph 2 & $12 / 98$ & & $12.2 \pm 3.3$ \\
\hline & Amph2 & 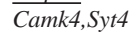 & $0 / 107$ & & $(2.8)$ \\
\hline & $A m p h 2$ & Hsp 74 & $1 / 107$ & & $0.9 \pm 0.9$ \\
\hline & Hsp74 & Lox & $12 / 106$ & & $11.3 \pm 3.1$ \\
\hline \multirow[t]{5}{*}{19} & $C d 5$ & $\underline{S h 3 d 3}$ & $6 / 66$ & $7 / 52$ & $11.0 \pm 2.9$ \\
\hline & $\underline{\operatorname{Sh} 3 d 3}$ & Ginl & $14 / 62$ & $7 / 58$ & $17.5 \pm 3.5$ \\
\hline & Ginl & $\underline{\operatorname{Sh} 3 d 5}$ & $5 / 80$ & $2 / 72$ & $4.6 \pm 1.7$ \\
\hline & $\underline{\operatorname{Sh} 3 d 5}$ & D19Mit17 & $4 / 53$ & $1 / 56$ & $4.6 \pm 2.0$ \\
\hline & $\overline{D 19 M}_{i t 17}$ & Nrap & $6 / 59$ & $6 / 64$ & $9.8 \pm 2.7$ \\
\hline
\end{tabular}

$\overline{{ }^{a} \text { Blot transfer methods and hybridization probes have been described previously for }}$ the marker loci used here (Kozak and Buckler 1997). Newly mapped genes are underlined.

${ }^{\mathrm{b}}$ Recombination distances were calculated according to Green (1981). Loci were ordered by minimizing the number of recombinants. No double recombinants were identified within these intervals. When no recombinants were identified, distances are given in parentheses and represent the upper level of the $95 \%$ confidence interval. Typing data were stored and analyzed with the program LOCUS developed by C.E. Buckler (NIAID, Bethesda, MD).

chromosome assignments for these genes by Southern blot analysis of a human $\times$ rodent somatic cell hybrid panel obtained from BIOS (New Haven, Conn.; Carlock et al. 1986). The panel consists of 19 human $\times$ hamster hybrids and one human $\times$ mouse hybrid. The $S h 3 d 3$ probe did not produce a clear human signal, but Dbn1l could be assigned to human Chr 7 and, based on its mouse location, is likely to map to 7p11-p13.

Our results indicate that these $\mathrm{SH} 3$ domain-containing proteins have a wide chromosomal distribution in mouse and human. Sev- eral of these genes show sequence homologies outside the SH3 domain, namely, the two amphiphysin genes and the small family consisting of SH3P4 (Sh3d2a), SH3P8 (Sh3d2b), and SH3P13 (Sh3d2c2) (Sparks et al. 1996; Giachino et al. 1997). However, these related genes are neither clustered nor map to chromosomes with known paralogous relationships as might be expected for families of genes derived by duplication and divergence. The remaining genes mapped in this study show little relatedness outside the SH3 domain, and, therefore, it is not surprising that they do not have clustered or paralogous map locations.

\section{Acknowledgments: Supported in part by an IATAP grant to H.C.M.}

\section{References}

Adamson MC, Silver J, Kozak CA (1991) The mouse homolog of the Gibbon ape leukemia virus receptor: genetic mapping and a possible receptor function in rodents. Virology 183, 778-781

Butler MH, David C, Ochoa GC, Freyberg Z, Daniell L, et al. (1997) Amphiphysin II (SH3P9; BIN1), a member of the amphiphysin/Rvs family, is concentrated in the cortical cytomatrix of axon initial segments and nodes of ranvier in brain and around $\mathrm{T}$ tubules in skeletal muscle. $\mathrm{J}$ Cell Biol 137, 1355-1367

Carlock LR, Smith D, Wasmuth JJ (1986) Genetic counterselection procedure to isolate interspecific cell hybrids containing single human chromosomes: construction of cell hybrids and recombinant DNA libraries specific for human chromosomes 3 and 4. Somatic Cell Mol Genet 12, 163-174

de Heuvel E, Bell AW, Ramjaun AR, Wong K, Sossin WS, et al. (1997) Identification of the major synaptojanin-binding proteins in brain. J Biol Chem 272, 8710-8716

Giachino C, Lantelme E, Lanzetti L, Saccone S, Della Valle G, et al. (1997) A novel SH3-containing human gene family preferentially expressed in the central nervous system. Genomics 41, 427-434

Green EL (1981) Genetics and probability in animal breeding experiments. (New York: MacMillan Publishing Co.)

Jenkins NA, Gilbert DJ, Yamamoto R, Kilimann MW, Copeland NG (1995) Amphiphysin (Amph) maps to the proximal region of mouse chromosome 13. Genomics 28, 363-365

Kadlec L, Pendergast AM (1997) The amphiphysin-like protein 1 (ALP1) interacts functionally with the $\mathrm{CABL}$ tyrosine kinase and may play a role in cytoskeletal regulation. Proc Natl Acad Sci USA 94, 12390-12395

Kozak CA, Buckler CE (1997) Fvc58, Fvspre, Skive. In Mouse Genome Database, Release 3.2, Mouse Genome Informatics, The Jackson Laboratory, Bar Harbor, Maine. World Wide Web (URL:http://www. informatics.jax.org/crossdata)

Kozak CA, Peyser M, Krall M, Mariano TM, Kumar C, et al. (1990) 
Molecular genetic markers spanning mouse chromosome 10. Genomics $8,519-524$

Ramjaun AR, Micheva KD, Bouchelet I, McPherson PS (1997) Identification and characterization of a nerve terminal-enriched amphiphysin isoform. J Biol Chem 272, 16700-16706

Ribon V, Herrera R, Kay B, Saltiel A (1998) A role for CAP, a novel, multifunctional $\mathrm{Src}$ homology 3 domain-containing protein in formation of actin stress fibers and focal adhesions. J Biol Chem 273, 4073-4080 Ringstad N, Nemoto Y, De Camilli P (1997) The SH3p4/Sh3p8/SH3p13 protein family: binding partners for synaptojanin and dynamin via a Grb2-like Src homology 3 domain. Proc Natl Acad Sci USA 94, 85698574
So CW, Caldas C, Liu M-M, Chen S-J, Huang Q-H, et al. (1997) EEN encodes for a member of a new family of proteins containing an Src homology 3 domain and is the third gene located on chromosome 19p13 that fuses to $M L L$ in human leukemia. Proc Natl Acad Sci USA 94, $2563-2568$

Sparks AB, Hoffman NG, McConnell SJ, Fowlkes DM Kay BK (1996) Cloning of ligand targets: systematic isolation of SH3 domaincontaining proteins. Nat Biotechnol 14, 741-744

Torrey T, Kim W, Morse HC III, Kozak CA (1998) Cloning, expression and genetic mapping of the mouse $\mathrm{SH} 3$ domain protein, SH3D2B. Mamm Genome 9, 74-75 